\title{
Using Conceptual Mapping for Learning to Affect Students' Motivation and Academic Achievement
}

\author{
Mohammed Abdullatif Almulla *(D) and Mahdi Mohammed Alamri (D) \\ Department of Curriculum and Instruction, Faculty of Education, King Faisal University, \\ Al Ahsa 31982, Saudi Arabia; mahdi@kfu.edu.sa \\ * Correspondence: maalmulla@kfu.edu.sa
}

Citation: Almulla, M.A.; Alamri, M.M. Using Conceptual Mapping for Learning to Affect Students' Motivation and Academic Achievement. Sustainability 2021, 13, 4029. https://doi.org/10.3390/ su13074029

Academic Editors: Susana Rodríguez and Antonio Valle

Received: 5 February 2021

Accepted: 31 March 2021

Published: 5 April 2021

Publisher's Note: MDPI stays neutral with regard to jurisdictional claims in published maps and institutional affiliations.

\begin{abstract}
Conceptual mapping tools have been used more and more for various educational purposes in recent years by academicians and educators. In addition, developments of technology that include conceptual mapping have a significant influence on education sustainability. Nevertheless, students' understanding and motivation in using conceptual mapping in the context of education sustainability has rarely been assessed. Thus, this study could be useful for developing and testing theories related to using conceptual mapping, as well as for practitioners who use conceptual mapping in education sustainability. Besides being used as a method of assessment, these mapping tools are used to improve the students' critical and analytical thinking skills and to facilitate the demonstration of relationships among concepts. Instead of using written or verbal descriptions, these tools utilise various diagrammatic relationships. The use of pictures, diagrams and visual illustrations are believed to facilitate the understanding of complex topics more readily. Therefore, this research aims to develop a new model that employs conceptual mapping for improving the motivation and achievements of students. A survey was distributed to 247 participants who are using conceptual mapping tools for learning, and the data were quantitatively analysed using structural equation modelling (SEM-Amos). The results of this study show that conceptual mapping can be used to increase students' understanding and motivation to improve their academic achievements.
\end{abstract}

Keywords: conceptual mapping; students' motivation and academic achievement

\section{Introduction}

Even though the use of visual representation of information is not a novel concept, their full benefits in education have only been realized recently. Flow charts were first used in the early seventies [1] while pie charts and other visual representation aids were reportedly used even before that [2]. In later years, complex philosophical questions and concepts were simplified using visual displays [3]. It has been reported that it was over 30 years ago that the formal use of mapping complex information appeared. Various mapping tools that are used for creating data visualization and establishing connection between concepts have emerged in the market in the last decade. These tools may be widely known as conceptual mapping, mind mapping or argument mapping. Conceptual mapping is a relationship-based tool that aids in understanding the association between different ideas and elements. Conceptual mapping uses domain-specific problem-solving methods that are based on understanding the central ideas of a topic in a meaningful and conceptual way [4]. Even though the terms conceptual mapping and mind mapping are sometimes used interchangeably [5,6], it is worth noting that conceptual mapping is more structured, precise and formal. However, it is less graphic as it uses hierarchical structures contrary to mind mapping which uses diagrams and pictures. A conceptual map, which usually starts with a question that needs an answer [7], is a hierarchical "tree" structure with superordinate and subordinate parts (primary, secondary and tertiary ideas). Yet, conceptual mapping can also be non-hierarchical or even data-driven where the input defines the shape of the map. Cognitive psychology introduces several processes, 
such as moderate constructivist approaches, by which schema, propositions, concepts or specific prototypes are formed [8]. Moderate constructivist approaches in learning [9] and the effects of active knowledge construction (for an overview, see [10]) have been well investigated. To create a constructivist student-centred learning experience, conceptual mapping can be applied [11]. Conceptual mapping helps a learner visualize concepts either as a beginner studying linear structures or as an expert looking at complex networks of knowledge domains. Conceptual mapping has been used in constructivist learning approaches in order to promote adult learners' comprehension of how ideas and concepts can be linked through dependable and stable networks and schemes [12]. Students should use conceptual mapping to distinguish associations between concepts and, as a result, better understand those concepts and the domains to which they belong [13]. Conceptual mapping techniques have been employed to improve academic learning [11,14,15], and positive outcomes have been shown as a result of their use [16]. When computer-based conceptual mapping tools were used in biology classes, students showed high acceptance of conceptual mapping in class [17]. The use of conceptual mapping in education has been used extensively to address a variety of issues and answer different questions in different educational stages including, but not limited to, higher education. The aim of this research is to add to the existing knowledge by developing a new model of using conceptual mapping in the motivation of students of higher education in Saudi Arabia and in turn improving their academic achievements.

\section{Conceptual Mapping Background}

According to the Center for Applied Special Technology (CAST, 2008 [18]), conceptual mapping is the use of visual representation to show the association and connection between various concepts, ideas and elements. The term "conceptual map" could also be known as a graphic organizer, a knowledge map or an advance organizer. Even though conceptual maps are known to aid in learning, they could be ineffective if they are used in the wrong learning phases or with the wrong learning styles. Furthermore, they could have certain drawbacks as they may inhibit critical thinking and confuse concept relationships [13]. Computer-based conceptual mapping is more efficient compared to the use of paper and a pencil as it can help while studying complex relationships, especially when making edits and revisions [19]. Conceptual mapping can also be used in visually expressing abstract concepts; a method that, though complex, can induce analytical and critical thinking [19]. It is a method that teaches learners knowledge construction by representing ideas visually and improving critical thinking, instead of rote memorization [20]. It is a tool not only useful to students, but also to teachers who can review and explore different concepts which they have not yet [21]. The main question of this research is: What are the conceptual mapping factors that affect students' motivation and students' achievements? Conceptual mapping assists in the academic challenge that is characteristic of active study, but not all students accept this struggle to completely grasp environment-as-connection [22]. As well, according to a previous study, higher-achieving students found concept mapping more difficult and developed more relation understanding [22].

This research considers using conceptual mapping for students' understanding and motivation in using conceptual mapping in the context of education sustainability. While the debate continues as to the best way to develop the competencies around sustainable development among students, there remains the significant challenge of adequately assessing the learning and understanding of individual students and the cohort as a whole about the topic [23]. Therefore, the objective of this research is to contribute more and select preferred definitions of sustainability, as well as to develop a model of using conceptual mapping for learning, to facilitate increased understanding and motivation and to increase the effectiveness of action taken to achieve education sustainability. This leads to an examination of the worldviews that underpin each student's conceptual mapping and the development of a framework to clarify sources of conceptual difference. Thus, this study primarily drew on sustainability literature from the field of sustainability education, 
an emphasis that corresponds to the perspectives of the students who participated in this study.

Most of the currently available and widely used methods of educational assessments do not encourage true understanding of subject matter but are based on literal memorization of the materials presented. According to [24], prospective teachers and environmental educators see concept mapping as a useful method for representing their understanding in environmental education, facilitating reflexive and collaborative learning, improving teaching communicative skills, and successfully integrating ICT into the classroom. As a result, environmental education in the twenty-first century necessitates well-trained teachers with strong teaching and communication skills. Conceptual mapping provides both a qualitative and quantitative indicator of conceptual comprehension, making it a useful complement or supplement to conventional pencil and paper assessments [25]. Conceptual mapping is a method of representing knowledge graphically or visually with concepts encircled in nodes or bubbles and the concept relationships by using labelled links or propositions [26]. "The idea of conceptual mapping is based on Ausubel's assimilation theory of cognitive learning whereby the mind organizes information in a hierarchical fashion from the top down as well as their interrelatedness of the concepts [26-28]." There are definitive differences between learning by memorization and learning by understanding according to Ausubel [21]. Conceptual and linguistic clarity, relatability and meaningfulness are crucial parts of any learning materials. True learning is established through questioning and discovery instead of repetition and memorization. The latter method of learning does not help learners build upon their existing knowledge nor does it enable them to understand outcomes in events or relationships among elements [27,29]. Conceptual mapping can be hierarchical, non-hierarchical or even data-driven where the input defines the shape of the map. Agglomerative cluster analysis is a form of data-driven conceptual mapping. This analysis comprises various textual terms appearing across a number of respondents which are then "clustered" to form a diagrammatic representation [30-33] (see Figure 1).

\section{KEY:}

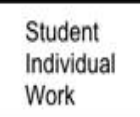

Work

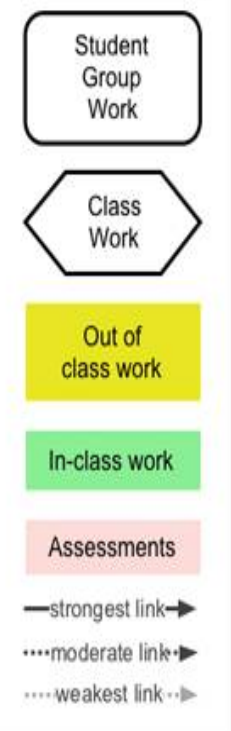

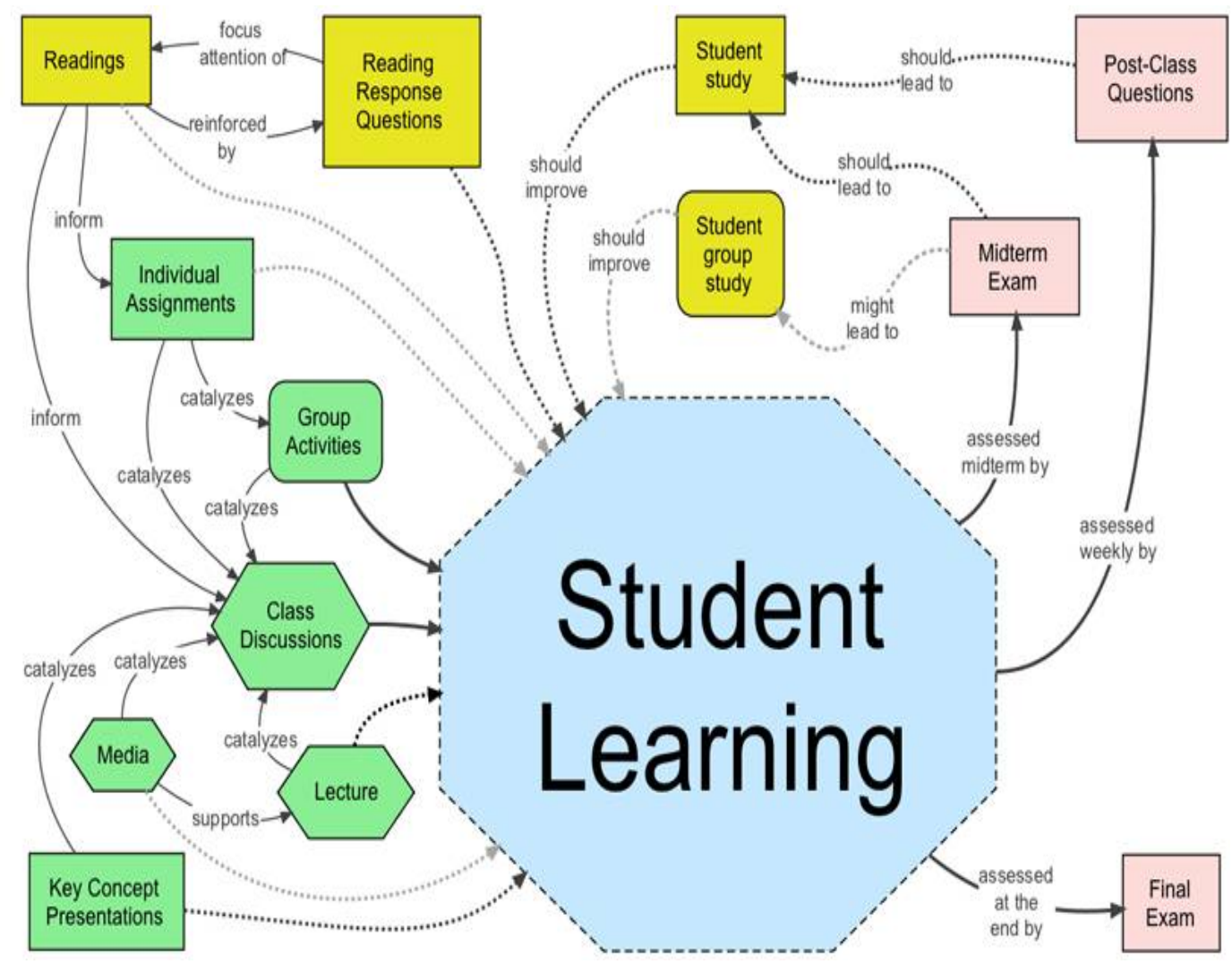

Figure 1. Conceptual mapping. 


\section{Research Theory and Hypotheses}

The use of collaborative learning which is based on the concept of making the learning process more engaging [34] has been broadly promoted in educational practices. According to [35], cognitive development is achieved by acquiring knowledge through social interaction. Collaborative conceptual mapping nurtures group metacognitive processes as it helps students maintain shared awareness during group interactions [36-38]. According to [39], a constructivism, developmental and interactive learning approach is the main scope of conceptual mapping. Theories of new information assimilation using critical thinking are the basis of the constructivism approach. The ability for learners to utilize conceptual mapping to cognitively process concepts that vary in their difficulty by applying and assessing their ideas using information organizers is what makes Hyerle advocate the use of conceptual mapping. Moreover, conceptual mapping supports interactive learning as learners use it to communicate their thoughts in shared group activities. The proposed research model of this study was developed using the following ten factors: the use of conceptual mapping (CM), attitude towards conceptual mapping (AT), behavioural intention to use conceptual mapping (BIU), collaborative conceptual mapping (CO), perceived usefulness of conceptual mapping (PU), students' interaction via use of conceptual mapping (SI), assessment and evaluation of use of conceptual mapping (AE), students' motivation to use conceptual mapping (SM), students' thinking while using conceptual mapping (ST) and students' achievement due to the use of conceptual mapping (SA) (see Figure 2).

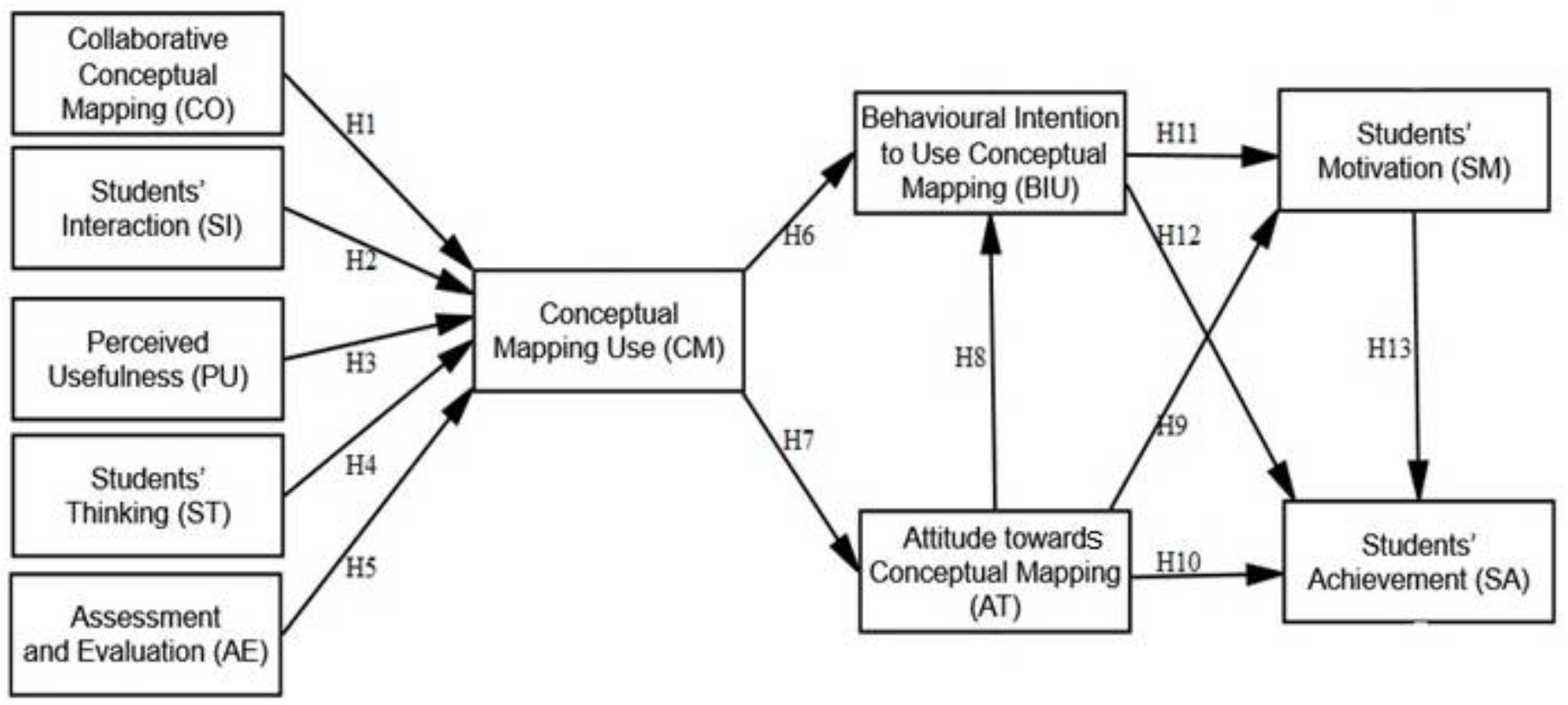

Figure 2. Research Model.

\subsection{Students' Collaboration}

Conceptual mapping is usually incorporated into collaborative learning activities by arranging participants into groups of three to five people and allowing them to construct their group concept mapping [40]. With the help of concept mapping team members are able to reach a consensus and capture ideas collectively via interaction, thus reaching a new level of understanding and cooperation [10]. According to South Dakota State University, one of the different types of conceptual mapping starts with a central idea and branches out with connected ideas [13]. Based on that, the following hypothesis was proposed:

Hypothesis 1 (H1). Students' collaboration is positively affected by the use of conceptual mapping. 


\subsection{Students' Interaction}

Conceptual mapping has been used to enable group learning and student collaboration in the classroom [41]. The interaction between individual and group cognitions is a crucial feature of collaborative learning [42]. Therefore, the following hypothesis was proposed:

Hypothesis 2 (H2). Students' interaction is positively influenced by conceptual mapping use.

\subsection{Perceived Usefulness}

Not only are conceptual maps an educational tool, but they can also be used in student assessments [43]. Heinze-Fry and Novak [44] compared a group of students who developed concept maps in a biology tutorial course to a control group. The conceptual mapping group achieved slightly higher mean scores on both a multiple-choice exam and an oral examination. In pharmacy education, this tool helps in recognizing associations between concepts learned in different courses [45]. Thus, the literature strongly suggests that conceptual maps are useful in helping learners identify links between new information and existing knowledge. Thus, the following hypothesis was proposed:

Hypothesis 3 (H3). Perceived usefulness is positively affected by conceptual mapping use.

\subsection{Students' Critical Thinking}

Even though educators might use visual aids to promote learning, they need to avert from using conceptual mapping tools that oppose critical thinking and problem solving, such as linear mapping or flow charts according to South Dakota State University [13]. According to Hyerle [39], the creator of "Critical Thinking, Inc.", conceptual mapping is a tool that shapes critical thinking skills. Based on the above discussion, the following hypothesis was proposed:

Hypothesis 4 (H4). Students' critical thinking is positively influenced by conceptual mapping use.

\subsection{Assessment and Evaluation}

Not only can conceptual mapping be employed for learning, but it can also be utilized for assessment and evaluation $[27,28,46]$. Using conceptual mapping, educators can discover student misunderstandings by examining their sketched connections in information organizers. Furthermore, they can support their students in making corrections by constant sharing, discussions and research. Based on the above, the following hypothesis was proposed:

Hypothesis $\mathbf{5}$ (H5). Assessment and evaluation are affected positively by the use of conceptual mapping.

\subsection{Conceptual Mapping Use}

Conceptual mapping is becoming more widely used in all areas of learning including science education to help learners develop their discipline or topic-based knowledge [47] and improve their problem-solving abilities [47]. Moreover, this tool emphasizes the pre-existing theoretical knowledge and helps learners elaborate on it and modify any misconceptions [20]. Therefore, the following hypotheses were proposed:

Hypothesis 6 (H6). Conceptual mapping use is positively influenced by the behaviour intention to use this tool.

Hypothesis 7 (H7). Conceptual mapping use is positively influenced by attitude towards this tool. 


\subsection{Attitude towards Conceptual Mapping}

According to research conducted by [48], learners who used conceptual mapping exhibited a more positive attitude compared to the control group. The same conclusion was also made by a one-year study that examined the students' attitude towards physics by [49]. This study examined the effect that the use of conceptual mapping has on the attitude of the students at the end of their courses and during practical lessons in addition to its potential uses for high-level learning and in cumulative final examinations. Based on the above, the following hypotheses were proposed:

Hypothesis $\mathbf{8}$ (H8). Attitude towards conceptual mapping is positively affected by behaviour intention to use conceptual mapping.

Hypothesis 9 (H9). Attitude towards conceptual mapping is positively affected by students' motivation.

Hypothesis 10 (H10). Attitude towards conceptual mapping is positively affected by students' achievements.

\subsection{Behavior Intention to Use Conceptual Mapping}

Behavioural intentions are personal guidelines that govern the way people behave [49]. Even though motives are the most important interpreter of actions, people do not often have enough influence over their behaviour to actually carry out their intentions, according to the principle of planned behaviour [50,51]. Taking that into consideration, this research expands the TAM model by adding behaviour intention to use conceptual mapping as an additional factor. Thus, the following hypotheses were proposed:

Hypothesis 11 (H11). Behaviour intention to use conceptual mapping is positively related to students' motivation.

Hypothesis 12 (H12). Behaviour intention to use conceptual mapping is positively related to students' achievements.

\subsection{Students' Motivation}

A German version of the Intrinsic Motivation Inventory (IMI), which is a multidimensional measurement device intended to assess participants' subjective experience related to a target activity [49], was used to measure motivational variables [51]. As expected, the motivation variable is affected by the utilization of conceptual maps while it is not influenced by lower computer user self-efficacy values indicating learners' computer-related difficulties in using digital concept mapping [51]. Based on that, the following hypothesis was proposed:

Hypothesis 13 (H13). Students' motivation to use conceptual mapping is positively affected by students' achievements.

\subsection{Students' Achievements}

Conceptual mapping has been recommended as an efficient tool for learning through map construction $[52,53]$. The study revealed that those students who used concept mapping before, during and after classes had higher achievement than groups that received the standard mode instruction. The main aim of teaching should be to help the learner acquire mastery over the presented concepts [47].

\section{Research Methodology}

The sample of the study was randomly selected from a population of undergraduate students who are active users of conceptual mapping for learning. Randomization is the 
best tool for reducing the effect of possible interfering factors because it tends to maintain strong internal validity. A single random survey often has strong external validity because the sample size is large enough: it reflects the characteristics of the larger population [54]. Data were collected from undergraduate students at King Faisal University in Saudi Arabia who are using conceptual mapping for learning (see the questionnaire in the Appendix A). Two hundred and seventy-three questionnaires were distributed, of which 268 were returned. From the returned questionnaires, 21 were eliminated as they were incomplete. All the remaining 247 responses were imported into the SPSS package software. To validate the model, confirmatory factor analysis was used. Structural equation modelling (SEM) was employed using AMOS. A quantitative study model was adopted using the questionnaire as a data collection tool. Following Krejcie and Morgan's approach, PLS-SEM was chosen as the primary statistical analysis method, with SPSS software used for data analysis [55]. A sufficient degree of reliability was determined through computing composite reliability. Initially, construct validity was achieved in two steps: first by calculating convergent validity and second by assessing discriminant validity. Convergent validity was verified in order to evaluate the model's fitness before assessing the hypotheses. This is done by three procedures: factor loadings, average variance extracted AVE and composite reliability. Furthermore, discriminant validity was assessed through the criterion test as described by [54]. In the subsequent stage, the structural model was assessed. Any inaccuracy that might arise in the outcomes may result from some exceptional cases, thus the data are not to be used in any future analysis according to [54]. The questionnaire used in this research was adopted from previous research in conceptual mapping [20,47], attitude towards conceptual mapping was adapted from [48], behavioural intention to use conceptual mapping was adapted from [50,56,57], collaborative conceptual mapping was adapted from $[40,58]$, perceived usefulness of conceptual mapping was adapted from [48], students' interaction via use of conceptual mapping was adapted from $[41,42,59]$, assessment and evaluation of use of conceptual mapping were adapted from $[27,28,46,60]$, students' motivation to use conceptual mapping was adapted from [51,61], students' critical thinking while using conceptual mapping was adapted from $[13,39]$, and students' achievement through conceptual mapping was adapted from $[47,53,60]$ (see the questionnaire in the Appendix A). To design the questionnaire, a five-point Likert scale was adopted for each of the items, with " 5 " indicating strong agreement and " 1 " indicating strong disagreement.

\section{Results and Analysis}

Demographic variables were categorized into three categories: gender, age and specialization. Regarding the gender of the participants, $149(60.3 \%)$ of the respondents identified as males and 98 (39.7\%) identified as females. One hundred and thirty-three $(53.8 \%)$ of the respondents were between the ages of 18 and $21,74(30.0 \%)$ were between the ages of 22 and 25,20 respondents (8.1\%) were between the ages of 26 and 29,13 (5.3\%) were between the ages of 30 and 33 , and $7(2.8 \%)$ were more than 34 years old (see Table 1$)$.

Table 1. Demographic variables.

\begin{tabular}{cccc}
\hline & Variables & Number & Percentages \% \\
\hline \multirow{2}{*}{ Gender } & Males & 149 & $60.3 \%$ \\
& Females & 98 & $39.7 \%$ \\
\hline \multirow{3}{*}{ Ages } & $18-21$ years old & 133 & $53.8 \%$ \\
& $22-25$ years old & 74 & $30.0 \%$ \\
& $26-29$ years old & 20 & $8.1 \%$ \\
& 30-33 years old & 13 & $5.3 \%$ \\
& More than 34 years old & 7 & $2.8 \%$ \\
\hline
\end{tabular}

Regarding their field of study, 69 (27.9\%) of the respondents were specializing in social science, 61 (24.7\%) in engineering, and 117 (47.4\%) were specializing in science and technology. Three criteria were used to evaluate the discriminant validity (DV). These 
were (1) the index among variables with a value less than 0.80 [54], (2) the AVE value of each construct which should be equal to or more than 0.50 , and (3) square of (AVE) of each construct which should be greater than the inter construct correlations (ICs) related to the factor [62]. Moreover, the results of the constructs, items and crematory factor analysis (CFA), with factor loading (FL) equal to or more than 0.70 , are considered acceptable with Cronbach's alpha (CA) and composite reliability (CR) values equal to or more than 0.70 [54].

\subsection{Measurement Model Analysis}

Structural equation modelling (SEM) was chosen as the primary statistical method for analysing data with confirmatory factor analysis (CFA) in AMOS 23. The measurement model was assessed through uni-dimensionality, reliability, convergent validity and discriminant validity. Hair et al. [54] suggested the use of maximum likelihood estimation procedures to conduct the model estimation by employing the guidelines of the goodness-of-fit, such as the normed chi-square, chi-square/degree of freedom, normed fit index (NFI), relative fit index (RFI), incremental fit index (IFI), Tucker-Lewis coefficient (TLI) comparative fit index (CFI), the parsimonious goodness of fit index (PGFI), the root mean square residual (RMR) and the root mean square error of approximation (RMSEA). Table 2 contains the summary of the goodness-of-fit indices which are used to evaluate the measurement model of this research.

Table 2. Summary of goodness-of-fit indices for the measurement model.

\begin{tabular}{ccc}
\hline Type of Measure & Acceptable Level of Fit & Values \\
\hline Chi-square $(\chi 2)$ & $\leq 3.5$ to 0 (perfect fit) and $(\rho>0.01)$ & $21.405 / 32$ \\
Root Mean Residual (RMR) & Close to 0 (perfect fit) & 0.032 \\
Normed Fit Index (NFI) & Value should be equal to or greater than 0.90. & 0.932 \\
Relative Fit Index (RFI) & Value should be equal to or greater than 0.90. & 0.917 \\
Incremental Fit Index (IFI) & Value should be equal to or greater than 0.90. & 0.922 \\
Tucker-Lewis Index (TLI) & Value should be equal to or greater than 0.90. & 0.931 \\
Comparative Fit Index (CFI) & Value should be equal to or greater than 0.90. & 0.926 \\
Root Mean Square Error of & Value below 0.10 indicates a good fit and & 0.037 \\
Approximation (RMSEA) & below 0.05 is deemed a very good fit. \\
\hline
\end{tabular}

Figure 3 shows the measurement model of the factors: students' collaboration and interaction while using conceptual mapping, perceived usefulness of conceptual mapping, students' critical thinking, students' assessment and evaluation, conceptual mapping use, students' attitude towards conceptual mapping, behavioural intention to use it, students' motivation to use conceptual mapping and students' achievement while using conceptual mapping. 


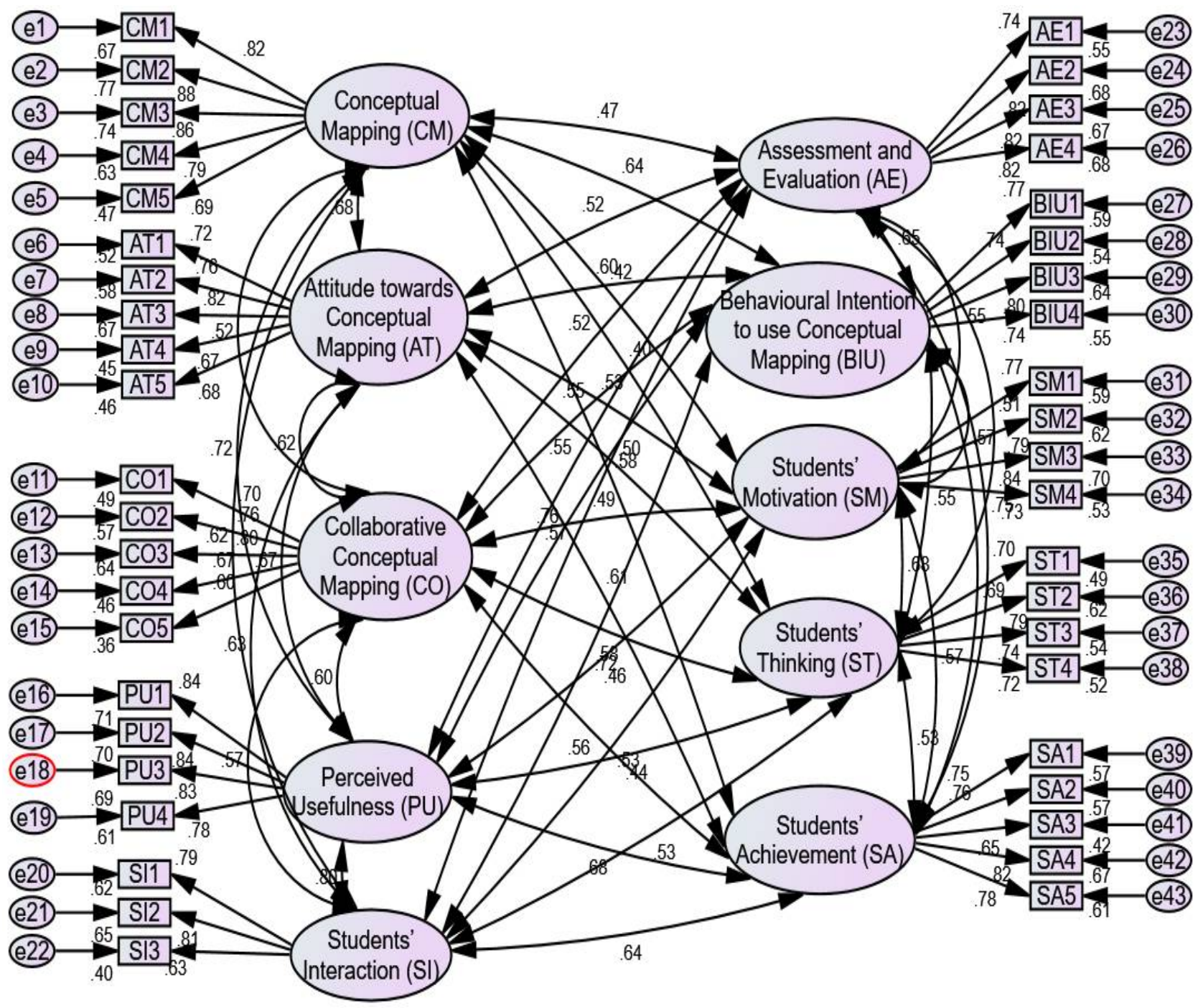

Figure 3. Measurement Model.

\subsection{Validity and Reliability of Measures Model}

Discriminant validity examines the level to which concepts and their indicators differ from one another [63]. All of the overall values of average variance extracted (AVE), composite reliability (CR) and Cronbach's alpha (CA) were accepted establishing discriminant validity (Table 3 ). The obtained AVE values ranged from 0.680 to 0.590 exceeding the minimum value of 0.50 with $p=0.001$. This suggests that discriminant validity is supported for all constructs [62]. According to [54], the correlations of items in any two constructs should not exceed the square root of both of their average variance. Furthermore, the obtained composite reliability (CR) and the Cronbach's alpha (CA) values exceeded the cut-off value of 0.70 , with a range of $0.976-0.873$ and 0.982 to 0.871 , respectively. The above results indicate that the entire factor loadings (FLs) are significant and surpass the minimum recommended value of 0.50 [54]. 
Table 3. Validity and reliability of the model.

\begin{tabular}{cccccccccccccc}
\hline & CM & AT & BIU & CO & PU & SI & AE & SM & ST & SA & CR & AVE & CA \\
\hline CM & 0.455 & & & & & & & & & & 0.911 & 0.617 & 0.890 \\
AT & 0.186 & 0.401 & & & & & & & & & 0.876 & 0.609 & 0.888 \\
BIU & 0.329 & 0.158 & 0.619 & & & & & & & & 0.938 & 0.590 & 0.982 \\
CO & 0.219 & 0.148 & 0.304 & 0.475 & & & & & & & 0.873 & 0.592 & 0.879 \\
PU & 0.257 & 0.084 & 0.424 & 0.284 & 0.598 & & & & & & 0.976 & 0.603 & 0.947 \\
SI & 0.258 & 0.159 & 0.401 & 0.311 & 0.378 & 0.612 & & & & & 0.874 & 0.671 & 0.889 \\
AE & 0.238 & 0.190 & 0.240 & 0.233 & 0.217 & 0.212 & 0.485 & & & & 0.971 & 0.680 & 0.906 \\
SM & 0.287 & 0.192 & 0.329 & 0.225 & 0.262 & 0.298 & 0.201 & 0.418 & & & 0.902 & 0.643 & 0.912 \\
ST & 0.291 & 0.208 & 0.339 & 0.264 & 0.308 & 0.317 & 0.262 & 0.320 & 0.496 & & 0.904 & 0.619 & 0.943 \\
SA & 0.235 & 0.197 & 0.290 & 0.242 & 0.248 & 0.244 & 0.228 & 0.269 & 0.324 & 0.475 & 0.896 & 0.597 & 0.871 \\
\hline
\end{tabular}

\subsection{Structural Model Analysis}

Path modelling analysis was employed to investigate the effects of the various factors of this model. The results are presented according to the conceptual mapping use. In the following step of the structural equation modelling (SEM), the confirmatory factor analysis (CFA) was conducted to test the thirteen proposed hypotheses (see Figure 4). As shown in Figure 4, twelve of the thirteen proposed hypotheses were accepted, and only one hypothesis was rejected. Table 4 displays the unstandardized coefficients and standard error values of the structural model showing good model key statistics and therefore indicating the model validity.

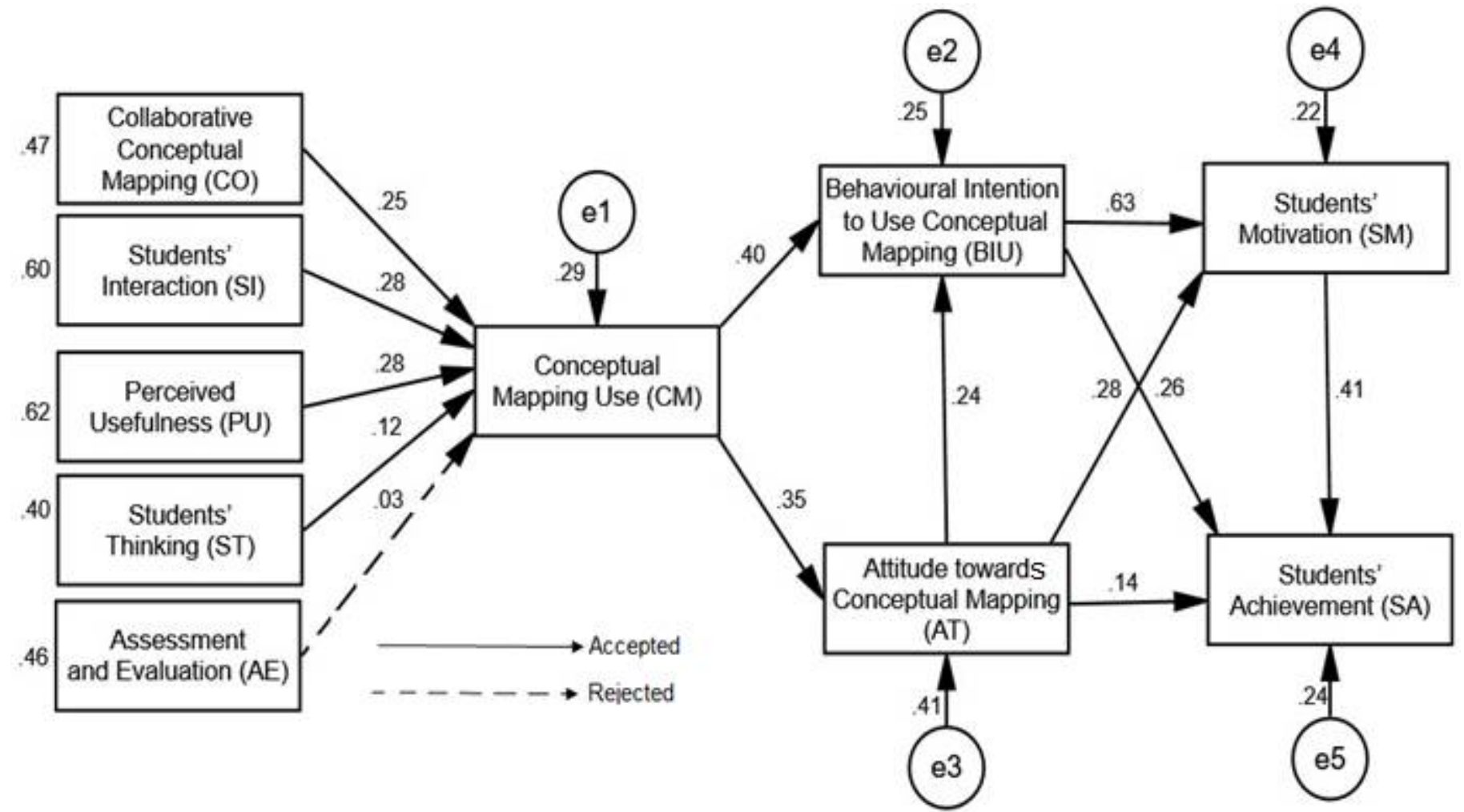

Figure 4. Results for the proposed model for conceptual mapping use. 
Table 4. Hypothesis testing results of the structural model.

\begin{tabular}{lllcccccc}
\hline & & & & Estimate & S.E. & C.R. & $p$-Value & Results \\
\hline H1 & CM & $\leftarrow$ & CO & 0.255 & 0.064 & 4.007 & 0.001 & Accepted \\
H2 & CM & $\leftarrow$ & SI & 0.280 & 0.064 & 4.345 & 0.001 & Accepted \\
H3 & CM & $\leftarrow$ & PU & 0.284 & 0.069 & 4.098 & 0.001 & Accepted \\
H4 & CM & $\leftarrow$ & ST & 0.117 & 0.061 & 1.896 & 0.058 & Accepted \\
H5 & CM & $\leftarrow$ & AE & 0.034 & 0.069 & 0.494 & 0.621 & Rejected \\
H6 & BIU & $\leftarrow$ & CM & 0.403 & 0.044 & 9.127 & 0.001 & Accepted \\
H7 & AT & $\leftarrow$ & CM & 0.346 & 0.052 & 6.618 & 0.001 & Accepted \\
H8 & BIU & $\leftarrow$ & AT & 0.238 & 0.050 & 4.799 & 0.001 & Accepted \\
H9 & SM & $\leftarrow$ & AT & 0.280 & 0.048 & 5.802 & 0.001 & Accepted \\
H10 & SA & $\leftarrow$ & AT & 0.140 & 0.053 & 2.626 & 0.009 & Accepted \\
H11 & SM & $\leftarrow$ & BIU & 0.630 & 0.052 & 12.136 & 0.001 & Accepted \\
H12 & SA & $\leftarrow$ & BIU & 0.262 & 0.068 & 3.844 & 0.001 & Accepted \\
H13 & SA & $\leftarrow$ & SM & 0.410 & 0.066 & 6.187 & 0.001 & Accepted \\
\hline
\end{tabular}

The first hypothesis testing results $(\beta=0.255, \mathrm{t}=4.007, p<0.001$ ) show that collaboration among students is positively impacted by conceptual mapping use. The results of the second hypothesis $(\beta=0.280, \mathrm{t}=4.345, p<0.001)$ demonstrate that students' interaction is positively influenced by the use of conceptual mapping. The testing results of the third hypothesis ( $\beta=0.284, t=4.098, p<0.001$ ) prove that the perceived usefulness of conceptual mapping is positively affected by the use of conceptual mapping. The fourth hypothesis testing results $(\beta=0.117, \mathrm{t}=1.896, p<0.001)$ show that students' critical thinking skills are positively impacted by conceptual mapping use. The results of the fifth hypothesis ( $\beta=0.034, t=0.494, p<0.001)$ demonstrate that assessment and evaluation were negatively influenced by the use of conceptual mapping. The testing results of the sixth hypothesis ( $\beta=0.403, \mathrm{t}=9.127, p<0.001)$ prove that the behavioural intention to use conceptual mapping is positively affected by the use of conceptual mapping. The seventh hypothesis testing results $(\beta=0.346, \mathrm{t}=6.618, p<0.001)$ show that the attitude towards the use of conceptual mapping is positively impacted by conceptual mapping use. The testing results of the eighth hypothesis $(\beta=0.238, t=4.799, p<0.001)$ prove that the attitude towards conceptual mapping is positively affected by the intention to use it. The results of the ninth hypothesis $(\beta=0.280, \mathrm{t}=5.802, p<0.001)$ demonstrate that students' attitude towards conceptual mapping is positively influenced by their motivation. The tenth hypothesis testing results $(\beta=0.255, \mathrm{t}=4.007, p<0.001)$ show that the attitude towards conceptual mapping is positively impacted by students' achievement while using conceptual mapping. The testing results of the eleventh hypothesis $(\beta=0.630, t=12.136, p<0.001)$ prove that the students' behavioural intention to use conceptual mapping is positively affected by their motivation to use it. The twelfth hypothesis testing results $(\beta=0.262, t=3.844, p<0.001)$ show that students' behavioural intention to use conceptual mapping is positively impacted by their achievement while using conceptual mapping. The results of the thirteenth and last hypothesis $(\beta=0.410, \mathrm{t}=6.187, p<0.001)$ demonstrate that students' motivation to use conceptual mapping is positively influenced by their achievement.

\subsection{Discussion}

Based on Table 4, 12 hypotheses were accepted and one hypothesis was rejected, showing that collaborative conceptual mapping, students' interaction, perceived usefulness, and students' thinking have a direct positive impact on conceptual mapping use. While assessment and evaluation have a direct negative impact on conceptual mapping use. As well, conceptual mapping use has a direct positive impact on behavioural intention to use conceptual mapping and attitude towards the use of conceptual mapping. Moreover, behavioural intention to use conceptual mapping has a direct positive effect on improving students' motivation and achievement. Similarly, attitude towards the use of conceptual mapping has a direct positive effect on the behavioural intention to use conceptual mapping and, in turn, has a direct positive effect on improving students' motivation 
and achievement. Finally, students' motivation has a direct positive effect on improving students' achievement.

Collaborative conceptual mapping nurtures group metacognitive processes as it helps students maintain shared awareness during group interactions and collaboration [38]. Therefore, using conceptual mapping for learning affects students' learning. Alamri et al. [64] found the relationship between collaboration and engagement as sustainability in higher education. In addition, it was shown that the hypotheses were supported and positively related to sustainability for education with interactivity with perceived usefulness, peers and interactivity with lecturers [65]. A significant relationship was found by [66] between perceived usefulness and attitudes towards the use of technology for education sustainability.

The findings of this study agree with some previous research that has claimed that allowing students to use novel technologies while learning can potentially inspire their extrinsic motivation and enhance their academic achievements. The factors that this paper considered to influence the use of conceptual mapping are conceptual mapping use (CM), attitude towards conceptual mapping (AT), behavioural intention to use conceptual mapping (BIU), collaborative conceptual mapping (CO), perceived usefulness of conceptual mapping (PU), students' interaction while using conceptual mapping (SI), assessment and evaluation using conceptual mapping (AE), students' motivation to use conceptual mapping (SM), students' critical thinking skills while using conceptual mapping (ST) and students' academic achievements while using conceptual mapping (SA). This research has substantial theoretical and practical contributions to the existing knowledge. In terms of theoretical contributions, this research adds to the current literature available on the use of conceptual mapping in education by taking into consideration the students' motivation to learn and their achievements. It also incorporates constructivism with critical thinking processes in an academic research context. At the same time, this research contributes practically by allowing educators to understand the relevant interactive factors and how they can affect students' use of conceptual mapping and subsequently their academic success. This study developed justified constructs and a verified measurement of a theoretical model to be used in education.

The sustainability framework should also assist educators and students in navigating through the multiplicity of sustainability meanings [67]. Student and cohort learning in sustainable development is assessed using conceptual mapping [23]. As a result, the findings of this study will be used to help with the collection and administration of sustainability awareness tests in a variety of academic programs and institutions. Student surveys are one of the most popular approaches for assessing student sustainability knowledge [68]. An investigation was carried out to illustrate the use of conceptual mapping for measuring student sustainability knowledge. Sustainability, according to Kioupi et al. [69], is an aspirational potential environment transformed by the Sustainable Development Goals, not a fixed condition. By focusing on the interconnections between each sustainability aspect, a holistic or integrative view uses paradoxical thought to accommodate this tension [70]. Similar to previous discussions over the definition of sustainable development [71], intellectual mapping will become a disputed and ultimately vacuous term. The recent research outlines three parameters that can be extended to a broad sample of conceptual mapping to determine discriminant validity. As a result, conceptual mapping may be used to further describe sustainability knowledge in order to direct and measure educational transformation efforts. Finally, by using conceptual mapping as part of a collaborative and interactive learning strategy, unique qualities of student sustainability knowledge that need to be enriched are clearly identified. As a result, student knowledge tests indicate the need for, a form of and results of initiatives to increase student understanding of sustainability (see Hypothesis H5). These selected factors and the developed instrument can help academic institutions analyse and measure the students' achievements in terms of their use of conceptual mapping. Finally, this study has various applications in the education sector in 
Saudi Arabia, especially in higher education institutions where they can make conceptual mapping an integral part of the learning experience. They can use conceptual mapping for:

- Studying the terms, facts and concepts of a particular subject;

- Classifying and categorizing information;

- Creating and assimilating information, ideas and concepts;

- Giving an overview of the "big picture" and finding connections among various concepts;

- Supporting creative thinking;

- Enhancing long-term memory skills;

- Developing higher-level thinking skills, strategies and habits;

- Utilizing illustrations effectively;

- Providing a wealth of information instantaneously;

- Developing knowledge understanding;

- Making new relations between already known concepts;

- Exploring new questions and solutions;

- As an aid in problem solving.

While this study presents the availability of statistical support, there are some limitations to this analysis. Respondents participating in this study are only from one university; thus, future studies need more respondents from different major backgrounds. An additional limitation of this study is that it utilizes questionnaires only. There was no qualitative data in the study, and thus the study was created from students' perceptions, which could vary from the educators' perception. Research in the future is recommended to duplicate the research in other states.

\section{Conclusions and Future Work}

This research aimed at developing a new model of using conceptual mapping in Saudi Arabia's higher education institutes to improve students' academic achievements. Various hypotheses were proposed to investigate the validity of this model. Based on the $p$-values, path coefficients, and the significance of the $t$-values, twelve of the hypotheses proposed were accepted, and only one was rejected. This research indicates that using conceptual mapping for learning improved the academic achievements of students through improving their attitude towards conceptual mapping, their behavioural intention to use conceptual mapping, collaboration amongst them while using conceptual mapping, the perceived usefulness of conceptual mapping, the students' interaction through conceptual mapping, the students' motivation to use conceptual mapping and the students' attitude towards the use of conceptual mapping. The results and model developed by this research can be used to examine the utilization of conceptual mapping to enhance students' achievement in other higher education institutes in Saudi Arabia and other countries; they are also generalizable to other populations and other age groups in higher education. In the future, developing a touch technology-based conceptual mapping system could have great applications in the education sector making it an idea worth considering for future studies. Not only will such a system permit students to develop their own conceptual maps, but it will also allow teachers to interact with students while they are learning. Furthermore, this proposed computerized solution will integrate teacher-centred conceptual mapping and student-centred touchscreen technology to support students in terms of improving their learning attitudes as well as their learning achievements. It is also worth looking at the impact of other cutting-edge touch technology, such as multi-touch interfaces, on students academic success in computational mapping-related learning tasks. Furthermore, since several prior studies have used different computerized conceptual mapping methods, future studies should equate the impact of touch technology-based concept mapping with other types of computerized concept mapping.

Author Contributions: Conceptualization, M.A.A. and M.M.A.; methodology, M.A.A. and M.M.A.; software, M.A.A. and M.M.A.; formal analysis, M.A.A. and M.M.A.; resources, M.A.A. and M.M.A.; 
writing-original draft preparation, M.A.A. and M.M.A.; writing-review and editing, M.A.A. and M.M.A. All authors have read and agreed to the published version of the manuscript.

Funding: This research was funded by Deanship of Scientific Research at king Faisal University grant number 1807016 .

Acknowledgments: The authors acknowledge the Deanship of Scientific Research at King Faisal University for the financial support under Raed Track (Grant No. 1807016).

Conflicts of Interest: The authors declare no conflict of interest.

\section{Appendix A}

Table A1. Questionnaire.

\begin{tabular}{|c|c|c|c|}
\hline Factors & $\begin{array}{l}\text { Items } \\
\text { Number }\end{array}$ & Code & Questions \\
\hline \multirow{5}{*}{ Conceptual mapping } & E1 & CM1 & Conceptual mapping helps me to learn better. \\
\hline & E2 & CM2 & $\begin{array}{l}\text { Conceptual mapping helps me to integrate and clarify the interrelationships } \\
\text { among curriculum contents. }\end{array}$ \\
\hline & E3 & CM3 & Conceptual mapping learning strategy stimulates me to think independently. \\
\hline & E4 & CM4 & Conceptual mapping helps me to enhance my interest in learning. \\
\hline & E5 & CM5 & Conceptual mapping can be a new learning approach. \\
\hline \multirow{5}{*}{$\begin{array}{l}\text { Attitude toward using } \\
\text { conceptual mapping }\end{array}$} & E6 & AT1 & I enjoy drawing conceptual maps to help me creating the concept. \\
\hline & E7 & AT2 & The conceptual maps I develop are useless to me in learning. \\
\hline & E8 & AT3 & I want to know more about the use of conceptual maps. \\
\hline & E9 & AT4 & Creating conceptual maps is time consuming. \\
\hline & E10 & AT5 & Using conceptual mapping is fun. \\
\hline \multirow{5}{*}{$\begin{array}{l}\text { Collaborative } \\
\text { conceptual mapping }\end{array}$} & E11 & $\mathrm{CO} 1$ & $\begin{array}{l}\text { Our group actively discuss the given topic while collaboratively creating our } \\
\text { group conceptual mapping. }\end{array}$ \\
\hline & E12 & $\mathrm{CO} 2$ & Our group conceptual map is closely related to my final composition. \\
\hline & E13 & $\mathrm{CO} 3$ & $\begin{array}{l}\text { During group conceptual mapping, each group member takes equal } \\
\text { responsibility in developing our group conceptual map. }\end{array}$ \\
\hline & E14 & $\mathrm{CO} 4$ & I feel that conceptual mapping facilitating our group discussion. \\
\hline & E15 & $\mathrm{CO} 5$ & Our group conceptual map represents our group's effort very well. \\
\hline \multirow{4}{*}{$\begin{array}{l}\text { Perception on the } \\
\text { usefulness of } \\
\text { conceptual mapping }\end{array}$} & E16 & PU1 & I think that conceptual mapping helps me organizing my ideas in learning. \\
\hline & E17 & PU2 & $\begin{array}{l}\text { I think that conceptual mapping helps me summarizing my understanding } \\
\text { of the topic. }\end{array}$ \\
\hline & E18 & PU3 & I think that conceptual mapping helps me planning a more creative learning. \\
\hline & E19 & PU4 & I felt that conceptual mapping improving the quality of my learning. \\
\hline \multirow{3}{*}{ Students' Interaction } & E20 & SI1 & $\begin{array}{l}\text { Using conceptual mapping in class facilitates interaction with group } \\
\text { members. }\end{array}$ \\
\hline & E21 & SI2 & $\begin{array}{l}\text { Using conceptual mapping in class gives me the opportunity to discuss with } \\
\text { group member. }\end{array}$ \\
\hline & E22 & SI3 & $\begin{array}{l}\text { Using conceptual mapping in class allows the exchange of information with } \\
\text { group members. }\end{array}$ \\
\hline \multirow{4}{*}{$\begin{array}{l}\text { Assessment and } \\
\text { Evaluation }\end{array}$} & E23 & AE1 & I feel most fulfilled when I use conceptual mapping in class. \\
\hline & E24 & AE2 & $\begin{array}{l}\text { I feel most fulfilled when I can solve a difficult problem by Using conceptual } \\
\text { mapping in class. }\end{array}$ \\
\hline & E25 & AE3 & $\begin{array}{l}\text { During using conceptual mapping in class, I feel most fulfilled when the } \\
\text { lecturer accepts my ideas. }\end{array}$ \\
\hline & E26 & AE4 & $\begin{array}{l}\text { During using conceptual mapping in class, I feel most fulfilled when other } \\
\text { students accept my ideas. }\end{array}$ \\
\hline \multirow{4}{*}{$\begin{array}{l}\text { Behavioural intention } \\
\text { to use conceptual } \\
\text { mapping }\end{array}$} & E27 & BIU1 & I intend to use the conceptual mapping learning strategy in other curricula \\
\hline & E28 & BIU2 & I intend to use conceptual mapping for learning \\
\hline & E29 & BIU3 & I intend to use conceptual mapping to assist me sharing learning content. \\
\hline & E30 & BIU4 & I intend to adapt the conceptual mapping strategy in my learning. \\
\hline
\end{tabular}


Table A1. Cont.

\begin{tabular}{|c|c|c|c|}
\hline Factors & $\begin{array}{c}\text { Items } \\
\text { Number }\end{array}$ & Code & Questions \\
\hline \multirow{4}{*}{ Students' Motivation } & E31 & SM1 & I am confident I will do well when using conceptual mapping for learning. \\
\hline & E32 & SM2 & I am motived when my lecturer using conceptual mapping in teaching. \\
\hline & E33 & SM3 & I am motived when I learn by using conceptual mapping. \\
\hline & E34 & SM4 & I am confident the projects will be good when I use conceptual mapping. \\
\hline \multirow{4}{*}{ Students' Thinking } & E35 & ST1 & \multirow{4}{*}{$\begin{array}{l}\text { During conceptual mapping use, I think about my options before I plan. } \\
\text { I can think of new ideas or other ways to solve a problem via using } \\
\text { conceptual mapping. } \\
\text { Using conceptual mapping promotes my critical thinking skill to solve a } \\
\text { problem. } \\
\text { Using conceptual mapping develops my ability to evaluate sources and } \\
\text { points of view in order to select the best option and solutions for the } \\
\text { problem. }\end{array}$} \\
\hline & E36 & ST2 & \\
\hline & E37 & ST3 & \\
\hline & E38 & ST4 & \\
\hline \multirow{5}{*}{ Students' Achievement } & E39 & SA1 & \multirow{5}{*}{$\begin{array}{l}\text { Using conceptual mapping improves my knowledge of the topic. } \\
\text { Using conceptual mapping promotes the retention of knowledge. } \\
\text { Using conceptual mapping helps me to gain focus on the content of the topic. } \\
\text { Using conceptual mapping helps me to receive an excellent grade in the } \\
\text { class. } \\
\text { Using conceptual mapping encourages me to be an autonomous learner. }\end{array}$} \\
\hline & $\mathrm{E} 40$ & SA2 & \\
\hline & E41 & SA3 & \\
\hline & E42 & SA4 & \\
\hline & E43 & SA5 & \\
\hline
\end{tabular}

\section{References}

1. Nassi, I.; Shneiderman, B. Flowchart Techniques for Structured Programming. Sigplan Not. 1973, 8, 12-26. [CrossRef]

2. Tufte, E.R. The Visual Display of Quantitative Information, 2nd ed.; Graphics Press: Cheshire, England, 1983.

3. Horn, R.E. Mapping Great Debates: Can Computers Think? MacroVU Press: Washington, WA, USA, 1998.

4. Sigler, E.; Saam, J. Teacher candidates' conceptual understanding. J. Sch. Teach. Learn. 2006, 6, 118-126.

5. Ahlberg, M. Varieties of concept mapping. In Proceedings of the First International Conference on Concept Mapping, Pamplona, Spain, 14-17 September 2004.

6. Slotte, V.; Lonka, K. Spontaneous concept mapping aiding the understanding of scientific concepts. Int. J. Sci. Educ. 1999, 21, 515-531. [CrossRef]

7. Novak, J.D.; Cañas, A.J. The Theory Underlying Concept Mapping and How to Construct Them; Florida Institute for Human and Machine Cognition: Florida, FL, USA, 2006; Technical Report IHMC Cmap Tools 2006-01 Retrieved 21/6/07; Available online: http:/ / cmap.ihmc.us/publications/researchpapers/TheoryUnderlyingConceptMaps.pdf (accessed on 1 December 2020).

8. Anderson, J. Cognitive Psychology and Its Implications; Worth Publishers: New York, NY, USA, 2004.

9. Mintzes, J.; Wandersee, J.; Novak, J. Teaching Science for Understanding: A Human Constructivist View; Elsevier: Oxford, UK, 2005.

10. Novak, J.D. Learning, creating, and using knowledge: Concept mapping as facilitative tools in schools and corporations. J. eLearning Knowl. Soc. 2010, 6, 21-30.

11. Kinchin, I. A knowledge structures perspective on the scholarship of teaching and learning. Int. J. Scholarsh. Teach. Learn. 2009, 3. [CrossRef]

12. Daley, B. Facilitating learning with adult students through concept mapping. J. Contin. High. Educ. 2002, 50, 21-33. [CrossRef]

13. Ehlen, P. The Disadvantages of Concept Mapping. Available online: https:// classroom.synonym.com/disadvantages-Conceptualmapping-6749212.html (accessed on 1 December 2020).

14. Lederman, N.; Latz, M. Knowledge structures in the preservice science teacher: Sources, development, interactions, and relationships to teaching. J. Sci. Teach. Educ. 1995, 6, 1-19. [CrossRef]

15. Sherborne, T. Mapping the curriculum: How concept mapping can improve the effectiveness of course development. In Knowledge Cartography: Software Tools and Mapping Techniques; Okada, A., Buckingham-Shum, S., Sherborne, T., Eds.; Springer: London, UK, 2009; pp. 183-198.

16. Coutinho, C.; Bottentuit Junior, J. Using concept mapping with postgraduate teachers in a web-based environment: An exploratory study. In Proceedings of the Workshop on Cognition and the Web: Information Processing. Comprehension and Learning, Granada, Spain, 24-26 April 2008; pp. 139-145.

17. Buntting, C.; Coll, R.; Campbell, A. Students views of concept mapping use in introductory tertiary biology classes. Int. J. Sci. Math. Educ. 2006, 4, 641668. [CrossRef]

18. Center for Applied Special Technology D/B/A C.A.S.T. Universal Design for Learning Guidelines Version 1.0. Wakefield, Author: 2008. Available online: http:/ / www.cast.org/publications/UDLguidelines/UDL-Guideleines_v1.0.doc (accessed on 17 November 2020). 
19. Chang, K.E.; Sung, Y.T.; Chang, R.B.; Lin, S.C. A new assessment for computer-based mapping. Educ. Technol. Soc. 2005, 8, 138-148.

20. Novak, J.D. Meaningful learning: The essential factor for conceptual change in limited or inappropriate propositional hierarchies leading to empowerment of learners. Sci. Educ. 2002, 86, 548-571. [CrossRef]

21. Novak, J.D.; Cañas, A.J. The Theory Underlying Concept Mapping and How to Construct Them; Florida Institute for Human and Machine Cognition: Florida, FL, USA, 2008; Technical Report IHMC CmapTools 2006-01 Rev 01-2008; Available online: http:/ / cmap.ihmc.us/Publications/ResearchPapers/TheoryUnderlyingConceptMapping.pdf (accessed on 1 December 2020).

22. Proctor, J.D.; Bernstein, J. Environmental connections and concept mapping: Implementing a new learning technology at Lewis \& Clark College. J. Environ. Stud. Sci. 2013, 3, 30-41.

23. Shallcross, D.C. Concept maps for evaluating learning of sustainable development. J. Educ. Sustain. Dev. 2016, 10, 160-177. [CrossRef]

24. Pontes-Pedrajas, A.; Varo-Martínez, M. Educative experience of the use of concept mapping in science and environmental teacher training programmes. J. Teach. Educ. Sustain. 2014, 16, 102-116. [CrossRef]

25. Andrews, K.E.; Tressler, K.D.; Mintzes, J.J. Assessing environmental understanding: An application of the concept mapping strategy. Environ. Educ. Res. 2008, 14, 519-536. [CrossRef]

26. Hilbert, T.S.; Renkl, A. Concept mapping as a follow-up strategy to learning from texts: What characterizes good and poor mappers? Instr. Sci. 2008, 36, 53-73. [CrossRef]

27. Novak, J.D. Clarifying with concept mapping. Sci. Teach. 1991, 58, 45-49.

28. Novak, J.D. How do we learn our lesson?: Taking students through the process. Sci. Teach. 1993, 60, 50-55.

29. Guvenc, H.; Un Acikgoz, K. The effects of cooperative learning and concept mapping on learning strategy use. Educ. Sci. Theory Pract. 2007, 7, 117-127.

30. Jackson, K.; Trochim, W. Concept mapping as an alternative approach for the analysis of openended survey responses. Organ. Res. Methods 2002, 5, 307-336. [CrossRef]

31. Jackson, R.; Harper, K.; Jackson, J. Teaching for accessibility: Effective practices, classroom barriers. In The Universally Designed; Rose, D., Meyer, A., Hitchcock, C., Eds.; Harvard Education Press: Cambridge, MA, USA, 2005; pp. $125-147$.

32. Trochim, W. An introduction to concept mapping for planning and evaluation. Eval. Program. Plan. 1989, 12, 1-16. [CrossRef]

33. Christopher, J. How Will I Deliver Conceptual Understanding? Available online: http://www.christopherxjjensen.com/2013/07/ 25/how-will-i-deliver-conceptual-understanding/ (accessed on 17 November 2020).

34. Dillenbourg, P. Collaborative-Learning: Cognitive and Computational Approaches; Elsevier: Oxford, UK, $1999 ;$ pp. 1-19.

35. Vygotsky, L.S. Mind in Society: In The Development of Higher Psychological Processes; Harvard University Press: Cambridge, MA, USA, 1980.

36. Roth, W.M.; Roychoudhury, A. The concept map as a tool for the collaborative construction of knowledge: A microanalysis of high school physics students. J. Res. Sci. Teach. 1993, 30, 503-534. [CrossRef]

37. Van Boxtel, C.; Van der Linden, J.; Kanselaar, G. Collaborative learning tasks and the elaboration of conceptual knowledge. Learn. Instr. 2000, 10, 311-330. [CrossRef]

38. Koufou, A.K.; Ergazaki, M.I.; Komis, V.I.; Zogza, V.P. Researching individual and collaborative pair learning in primary school students using digital knowledge mapping for science education. In Digital Knowledge Mapping in Education; Springer: New York, NY, USA, 2014; pp. 139-159.

39. Hyerle, D. Thinking mapping: Seeing is understanding. Educ. Lead. 1995, 53, 85-89.

40. Chiu, C.H.; Huang, C.C.; Chang, W.T. The evaluation and influence of interaction in network supported collaborative concept mapping. Comput. Educ. 2000, 34, 17-25. [CrossRef]

41. Wang, M.; Cheng, B.; Chen, J.; Mercer, N.; Kirschner, P.A. The use of web-based collaborative concept mapping to support group learning and interaction in an online environment. Internet High. Educ. 2017, 34, 28-40. [CrossRef]

42. Hedlund, G.; Nonaka, I. A model of knowledge management and the N-Forum Corporation. Strateg. Manag. J. 1994, 15, 73-90. [CrossRef]

43. Hill, L.H. Concept mapping in a pharmacy communications course to encourage meaningful student learning. Am. J. Pharm Educ. 2004, 68, 1-9. [CrossRef]

44. Heinze-Fry, J.A.; Novak, J.D. Concept mapping brings long term movement towards meaningful learning. Sci. Educ. 1990, 74, 461-472. [CrossRef]

45. Qadir, F.; Zehra, T.; Khan, I. Use of concept mapping as a facilitative tool to promote learning in pharmacology. J. Coll. Physicians Surg. Pak. 2011, 21, 476-481.

46. Kern, C.; Crippen, K.J. Mapping for conceptual change. Sci. Teach. 2008, 75, 32-38.

47. Aziz, T.; Rahman, A. Effect of Concept Mapping Strategy on Students' Achievement in Science at Secondary Level. Research Gate. Available online: https://www.researchgate.net/publication/281848894 (accessed on 17 September 2015).

48. Karakuyu, Y. The effect of concept mapping on attitude and achievement in a physics course. Int. J. Phys. Sci. $2010,5,724-737$.

49. Broggy, J.; Mcclelland, G. Undergraduate Students' Attitudes Towards Physics after A Concept Mapping Experience; University of Limerick: Limerick, Ireland, 2008.

50. Triandis, H.C. Values, attitudes, and interpersonal behavior. In Nebraska Symposium on Motivation; Howe, H., Page, M., Eds.; University of Nebraska Press: Lincoln, NB, USA, 1980; Volume 27, pp. 195-259. 
51. Schaal, S. Cognitive and motivational effects of digital concept mapping in pre-service science teacher training. Procedia-Soc. Behav. Sci. 2010, 2, 640-647. [CrossRef]

52. Fraser, K.; Edwards, J. The effects of training in concept mapping on student achievement in traditional classroom tests. Res. Sci. Educ. 1985, 15, 158-165. [CrossRef]

53. Jegede, O.J. Inyang Nsendu Gender difference and achievement in integrated science among junior secondary school students: A Nigerian Study. Intl. Rev. Educ. 1990, 36, 364-368. [CrossRef]

54. Hair, J.F.; Sarstedt, M.; Ringle, C.M.; Mena, J.A. An assessment of the use of partial least squares structural equation modeling in marketing research. J. Acad. Mark. Sci. 2012, 40, 414-433. [CrossRef]

55. Krejcie, R.V.; Morgan, D.W. Determining sample size for research activities. Educ. Psychol. Meas. 1970, 30, 607-610. [CrossRef]

56. Ajzen, I. From intentions to actions: A theory of planned behavior. In Action Control: From Cognition to Behavior; Kuhl, J., Beckmann, J., Eds.; Springer: Berlin, Germany, 1985; pp. 11-39.

57. Ajzen, I. The theory of planned behavior. Organ. Behav. Hum. Decis. Process. 1991, 50, 179-221. [CrossRef]

58. Lee, Y. Collaborative Concept Mapping as a Pre-Writing Strategy for L2 Learning: A Korean Application. Int. J. Inf. Educ. Technol. 2013, 3, 254-258. [CrossRef]

59. Liu, T.C.; Liang, J.K.; Wang, H.Y.; Chan, T.W.; Wei, L.H. Embedding educlick in classroom to enhance interaction. In Proceedings of the International Conference on Computers in Education (ICCE), Hong Kong, China, 12 February 2003; pp. 117-125.

60. Tuan, H.L.; Chin, C.C.; Shieh, S.H. The development of a questionnaire to measure students' motivation towards science learning. Int. J. Sci. Educ. 2005, 27, 639-654. [CrossRef]

61. Glynn, S.M.; Brickman, P.; Armstrong, N.; Taasoobshirazi, G. Science motivation questionnaire II: Validation with science majors and nonscience majors. J. Res. Sci. Teach. 2011, 48, 1159-1176. [CrossRef]

62. Fornell, C.; Larcker, D.F. Evaluating structural equation models with unobservable variables and measurement error. J. Mark. Res. 1981, 1, 39-50. [CrossRef]

63. Bagozzi, R.P. Evaluating Structural Equation Models with Unobservable Variables and Measurement Error: A Comment. J. Mark. Res. 1981, 18, 375-381. [CrossRef]

64. Alamri, M.M.; Almaiah, M.A.; Al-Rahmi, W.M. The Role of Compatibility and Task-Technology Fit (TTF): On Social Networking Applications (SNAs) Usage as Sustainability in Higher Education. IEEE Access 2020, 8, 161668-161681. [CrossRef]

65. Alamri, M.M.; Almaiah, M.A.; Al-Rahmi, W.M. Social media applications affecting Students' academic performance: A model developed for sustainability in higher education. Sustainability 2020, 12, 6471. [CrossRef]

66. Al-Rahmi, W.M.; Alzahrani, A.I.; Yahaya, N.; Alalwan, N.; Kamin, Y.B. Digital communication: Information and communication technology (ICT) usage for education sustainability. Sustainability 2020, 12, 5052. [CrossRef]

67. Whyte, P.; Lamberton, G. Conceptualising Sustainability Using a Cognitive Mapping Method. Sustainability 2020, $12,1977$. [CrossRef]

68. Watson, M.K.; Pelkey, J.; Noyes, C.R.; Rodgers, M. Use of Concept Maps to Assess Student Sustainability Knowledge. In Proceedings of the ASEE Annual Conference and Exposition, Indianapolis, IN, USA, 15 June 2014.

69. Kioupi, V.; Voulvoulis, N. Education for sustainable development: A systemic framework for connecting the SDGs to educational outcomes. Sustainability 2019, 11, 6104. [CrossRef]

70. Sinakou, E.; Donche, V.; Boeve-de Pauw, J.; Van Petegem, P. Designing powerful learning environments in education for sustainable development: A conceptual framework. Sustainability 2019, 11, 5994. [CrossRef]

71. Connelly, S. Mapping sustainable development as a contested concept. Local Environ. 2007, 12, 259-278. [CrossRef] 